\title{
An editing tool based on cognitivism theory to support distance learning
}

\author{
Rafael G. Orbolato, Vânia P. de Almeida and Júnia C. A. Silva \\ Department of Computer Science, Federal University of São Carlos, Brazil
}

\begin{abstract}
This work, supported by FAPESP, explores the possibility of developing a computer-based tool, more specifically, an editor that contains cognitive strategies to help teachers in their task of creating material that promotes active learning, reducing knowledge acquisition complexity. A prototype version tool is presented with some cognitive strategies that promote active learning and that can be applied in the distance learning context.
\end{abstract}

Key words: cognitive strategies, distance learning (DL), active learning

\section{INTRODUCTION}

In the literature, references about many DL computer-based environments can be found, such as WebCT, LearningSpace and TopClass (see their respective web-sites). Among the environments analysed in our research, it was verified that in the majority of cases there was no didactical help for teachers in the creation of their material for students.

The environments usually do not have one specific editor for material creation, which allows teachers to choose freely, as the creation is not limited to one specific tool. On the other hand, these environments offer teachers the responsibility for creating quality material in many diverse respects: pedagogical, aesthetic, structural, etc.

Considering this background, a computer tool based on cognitive strategies to promote active learning is proposed. This tool will provide support to the teacher to edit and organise material, making understanding of the content easier for the students.

West (West, Farmer and Wolff, 1991, and cited in Liebman, 1998) suggests the adoption of active learning as follows - 'if information is 
actively processed in the brain before being stored in long-term memory, that information is more likely to be understood and retained'. Therefore, increasing active learning in classrooms will increase the students' chance to understand, remember and use acquired knowledge.

This short paper is organised in the following way: in Section 2 the cognitive strategies will be presented; in Section 3 the prototype of the computer-based tool that is being developed will be presented, and some final considerations will be discussed in Section 4.

\section{COGNITIVE STRATEGIES TO PROMOTE ACTIVE LEARNING}

Teachers can reduce learning complexity by providing students with a structured approach, showing them how to tackle the problem. To promote active learning, Liebman suggests the use of strategies based on concepts of cognitivism, called cognitive strategies. The cognitive strategies to promote active learning proposed by Liebman (1998) are:

- Organising: which includes applying taxonomies, listing similarities or differences, analysing form and function and itemising advantages and disadvantages.

- Framing: with visual displays of the underlying structure of related information. An example of framing is the creation of a table.

- Concept Maps: diagrams used to express temporal, categorical, causal, hierarchical and other relationships.

- Metaphors and Analogies.

- Rehearsals: strategies to keep the material being processed in the students' working memories long enough that they can more firmly establish it in their long-term memories. They include repeating, questioning and answering, predicting and clarifying, restating or paraphrasing, reviewing and summarising, selecting which information is important, taking notes and underlining.

- Advance Organisers: remarks by teachers to help students move to new topics. They can be understood as connectors or bridges, pointing out similarities, differences and relationships among subjects.

Based on these proposed strategies and knowing the level of difficulty of didactic material creation and organisation, a computational tool to support the teacher in this task and to facilitate knowledge acquisition is being created. 


\section{ACTIVE LEARNING COMPUTER-BASED TOOL SUPPORT}

In this work cognitive strategies are being implemented in an editor, in a prototype version, that is expected to be user-friendly and from which the material created in it will facilitate learning.

In Figure 1 the mockup of the prototype can be seen where $\mathbf{A}(1,2,3)$ are the common editing insertion options like text and images. The insertion options of cognitive strategies are the main focus of this work. The teacher, selecting a cognitive strategy, activates the respective module that will help during the necessary steps of editing using this strategy. In $\mathbf{B}(1,2,3)$ the positioning of the blocks that compose the material that is being created by the teacher can be seen. The positioning of these blocks is made by the teacher.

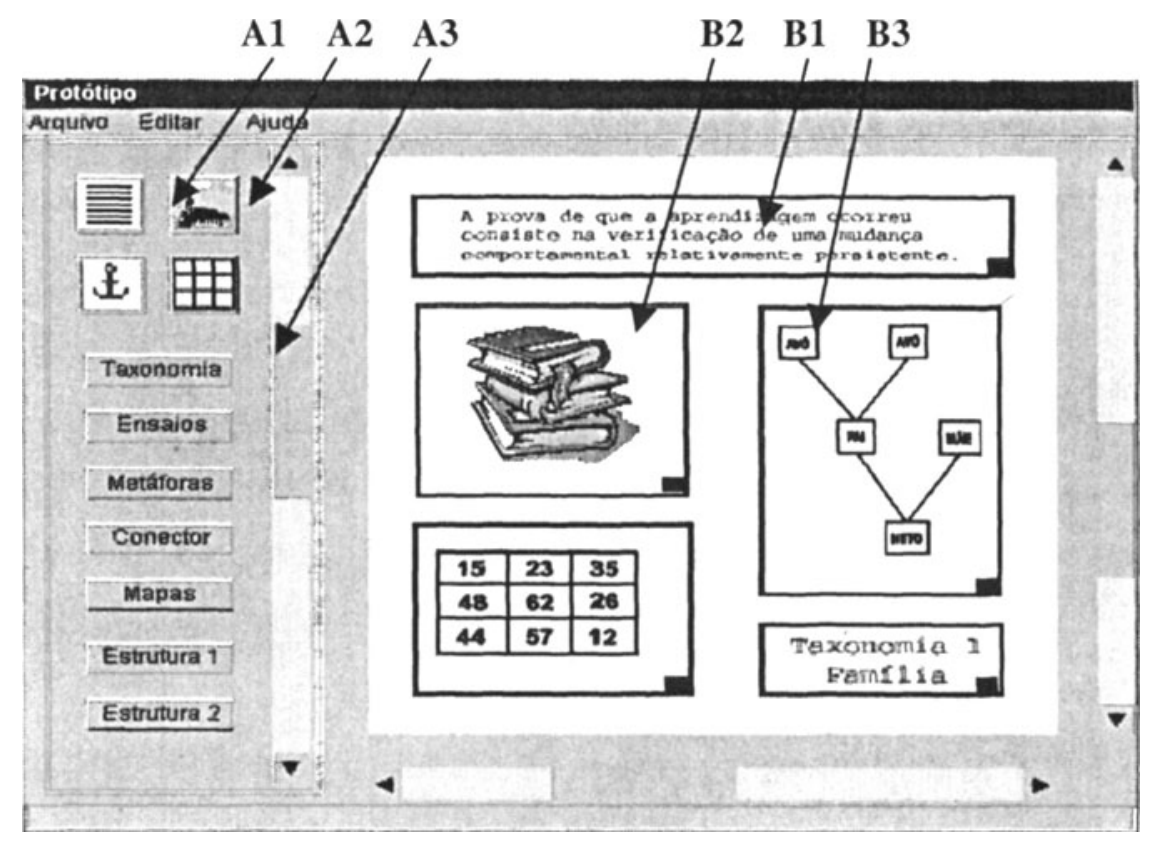

Figure 1. Computational tool screen with editing and positioning options marked

The items identified in Figure 1 are described as follows:

A1 - Text Editing Module: basic text editing options such as font formatting, text alignment and link insertion are offered. A text insertion can be seen in Figure 1 in Item $B 1$.

$\boldsymbol{A 2}$ - Image Insertion Module: allows the user to insert images. An image insertion can be seen in Figure 1 in Item $\boldsymbol{B 2}$. 
A3 - Taxonomy Editing Module: allows the user to generate a taxonomy. The teacher can use this module to organise related information. A taxonomy insertion can be seen in Figure 1 in Item $B 3$.

The project and implementation of other modules referring to other activities associated with the cited strategies such as advance organisers, concept maps, rehearsals, analogies and metaphors, etc. are foreseen.

\section{FINAL CONSIDERATIONS}

The cognitive strategies studied in this work were chosen as a base to help teachers in the creation of didactic material. Although other concrete forms of helping teachers should be studied and implemented in DL computer- based environments, this looks forward to a better learning process. The prototype will be developed and tested to verify what novice and experienced teachers, in technical respects, as well as in pedagogical respects related to the use of DL computer-based environments, think of its utilisation. Didactic material using the editor, for tests of the implemented strategies, verifying the quality of the obtained result and the opinion of students that use it, will also be created. The editor will be inserted in a DL computer-based environment for more general and accurate tests. The tool will allow the teacher to apply cognitive strategies in a simple and organised way, enriching the pedagogical quality of didactic material which is the main contribution proposed in this work.

\section{REFERENCES}

Learning Space. Available at: http://www.ilinc.com/ (last visited in 12/2001)

Liebman, J. (1998). Teaching Operations Research: Lessons from Cognitive Psychology. Interfaces, 28, 2, 104-110

TopClass. Available at: http://www.wbtsystems.com/ (last visited in 12/2001)

WebCT. Available at: http://www.webct.com/ (last visited in 12/2001)

West, C.K., Farmer, J.A. and Wolff, P.M. (1991) Instructional Design: Implications from

Cognitive Science. Boston, MA: Allyn and Bacon

\section{BIOGRAPHIES}

Rafael Godoi Orbolato is a master's degree student at DC-UFSCar. Vania Paula de Almeida is an undergraduate student at DC-UFSCar. Junia Coutinho Anacleto Silva is an assistant professor at DC-UFSCar. 